\title{
Cloud Computing Based E-learning in Malaysian Universities
}

\author{
https://doi.org/10.3991/ijet.v15i08.11798
}

\author{
Lubna A. Hussein ${ }^{(凶)}$, Mohd Faiz Hilmi \\ Universiti Sains Malaysia, Penang, Malaysia \\ lubnafatlawi@gmail.com
}

\begin{abstract}
Cloud computing is considered as a new innovation which essentially influences teaching and learning forms in the educational sector. Utilizing this innovation, not as it were, upgrades the quality of teaching and learning, but also diminishes overhead consumption of instructive education. In spite of the beneficial points of interest of cloud computing, in any case, its adoption is still distant from its full potential, particularly in university settings. However, not a large number of studies exist in regard to the adoption of cloudbased e-learning systems. Thus, this research is aimed to develop a theoretical research model for the adoption of cloud computing in Malaysian universities. For this purpose, the TAM model is used to represent the research framework. Moreover, a survey was conducted among 265 cloud-based e-learning participants and analysed via Structural Equation Modelling (SEM). The results indicate that the adoption of cloud-based e-learning is influenced by need and perceived usefulness, although innovativeness is not significant in the intention to adopt cloud-based e-learning.
\end{abstract}

Keywords - Cloud based e-learning, TAM model, innovativeness, Malaysian universities.

\section{$1 \quad$ Introduction}

One of the fundamental foundations holding strong ties with business-related organizations, particularly the government, is higher education [1,2]. In addition to this, the future of the education system consists of a growing utilization of technology which holds a significant influence on the quality of teaching and works towards the betterment of learning in all educational stages. Nowadays, due to lower enrolment rates and less physical presence of students in classes, various colleges and universities provide the option of distance learning for certain courses and sometimes even degree programs. This also takes place via online platforms, with many other different teaching models.

One of the quickly ascending and novel topics in the field of IT is called cloud computing. This sector of information technology has become extremely appealing towards various educational institutions since it possesses beneficial features including geographic distribution, cost-effectiveness in regard to automated systems 
as well as related open-source software. Generally, due to insufficient financial resources, educational institutions of smaller scale are not able to utilize IT to its full extent. However, cloud computing provides the capability of quality education in such institutions, particularly in remote areas with inadequate service and divided groups. Moreover, through strengthening the communication among students and educators located in a diverse geographical setting, it offers an opportunity to set up lively and interactive learning platforms, work actively in groups and discover more efficient and novel learning methods [3].

In order to address this gap, the aim of this study is to perform an empirical investigation regarding factors impacting cloud computing based e-learning systems in universities across Malaysia. By applying the TAM model, a theoretical framework is proposed in this research.

This paragraph gives a brief description regarding the organization of this paper. Prior to Section 3, entitled "Related Work", a summary of related studies is provided. In Section 4, the proposed theoretical framework is introduced. Section 5 consists of the research methodology. Furthermore, a detailed explanation is given regarding the testing of the model in Section 6. Ultimately, the final section includes the discussion and conclusion of this paper.

\section{Background of the Study}

\section{$2.1 \quad$ E-learning}

Ali [4] has defined e-learning as a technique using which users are enabled to advance their learning via a large number of tools namely personal computers, notebooks, mobile phones, laptops, tablets, etc. Furthermore, towards knowledge enhancement and, therefore, definite and more efficient performance, e-learning employs technologies involving information, communication and the Internet. Various applications, such as web-based learning, computer-based learning, virtual classrooms and digital collaboration, can be associated with e-learning [5].

Some of the benefits of e-learning for learners include saving the trouble of traveling between classrooms as done in traditional education, real-time broadcasting of the latest corresponding information such as policies, ideas and concepts as well as ensuring that the coursework remains up-to-date and updated as much as needed.

In spite of everything, because of various expenses related to network hardware such as servers, storage devices, etc, developing e-learning platforms can be extremely costly [6]. Aside from that, another major issue in this regard is a shortage in platform design as well as management staff [7].

\subsection{Cloud computing}

Cloud computing possesses a number of existing definitions. For instance, according to the National Institute of Standards and Technology (NIST), cloud computing is a "model for enabling convenient, on-demand network access to a 
shared pool of configurable computing resources (e.g., networks, servers, storage, applications, and services) that can be rapidly provisioned and released with minimal management effort or service provider interaction" [8].

Sharing services and platforms such as Dropbox and Google Drive are the most commonly-used cases of cloud computing. Moreover, cloud computing has proven to be advantageous in fields differing from business. Also, considering the popularity of online learning which is increasing at an exponential rate, investigating ways through which one can overcome the challenges that companies and learning environments related to e-learning face becomes crucial [9]. Since cost efficiency is the most major power of cloud computing, utilizing such a technology aids in the enhancement of cost effectiveness regarding e-learning [7].

With the utilization of cloud computing, users are no longer required to invest in building and maintaining infrastructure related to information technology. When in need of computing resources such as application software, all that needs to be done is to obtain the corresponding facilities from another organization which acts as a third party, after which one can easily gain access to the aforementioned service through the Internet. In exchange, due to the usage of computing power, users can send their payment to the service providers. Simply put, users of the cloud environment are enabled to bring their expenses regarding hardware resources and maintenance in relation to information technology to a minimum as they are not required to purchase any hardware or software in order to run business-related applications [10].

\subsection{Cloud-based E-learning systems}

Cloud-based e-learning systems are the future of the e-learning technology and related infrastructure. A cloud-based e-learning system is stated to be a subdivision of cloud computing in regard to the field of education. Furthermore, towards strengthening the traditional e-learning infrastructure, it is in possession of all supplies including both hardware and software resources. After the virtualization of study materials related to e-learning systems in cloud servers, they will be ready to be rented from cloud vendors and utilized by learners and related educational businesses [10].

Through sharing pools of configurable resources namely servers, applications and services, cloud computing has overcome the challenge of high costs in regard to elearning $[7,11]$.

As stated in previous research [12], implementing e-learning with the technology of cloud computing provides various benefits as follows:

- Lower costs: Using the cloud environment provided by their personal computers, mobile phones and tablets, users are enabled to run all related applications with minimum configuration of internet connection.

- Enhanced performance: No performance-related issues occur as client machines function because many of the corresponding applications and processes of cloudbased e-learning applications are already reserved in the cloud. 
- Immediate software updates: E-learners always receive updates immediately. This is due to the fact that all software is updated automatically in the cloud source, as a result of cloud-based e-learning applications running with cloud power.

- Strengthened compatibility regarding document formats: E-learning applications running on cloud power possess much more enhanced compatibility with various formats of files and fonts which might not be read properly in certain personal computers or mobile phones.

- Advantageous for learners: Cloud-based e-learning provides a large number of benefits for students. For instance, almost all their student work can be done online, including taking courses, taking part in examinations, receiving feedback from their teachers as well as sending and receiving projects and assignments to and from their instructors.

- Beneficial for instructors: Various advantages can also be gained by teachers from cloud-based e-learning. Many of their tasks can be performed online, such as preparing test papers, composing learning resources of more advanced content for students via content management, assessing students' tests, homework and projects, sending feedback to students and communicating with them in online forums.

\section{Related Work}

Prior works of research exist on the subject of cloud computing. In spite of that, either these studies have been conceptual or the focus of a large number of them has been on the infrastructure related to cloud computing in the higher education. Also, cloud computing is currently being applied in various universities across developed nations, namely the United States and the United Kingdom $[2,13]$.

Previous research has taken place by Shahzad et al. [14] in which they have discussed the advantages and corresponding challenges regarding the utilization of cloud technologies in the Malaysian higher education system. According to their study, many benefits can be gained from this technology in institutions of higher education, particularly in regard to world ranking of these educational institutions. However, a number of challenges are simultaneously being faced by the technology of cloud computing, including problems related to security and privacy, inadequate professionalism and low Internet speeds in certain locations. Nevertheless, due to this technology's many beneficial factors such as the capability of solving problems at lower expenses as well as easier sharing, access and management of information, it has a tremendous potential to further be developed.

As mentioned in previous studies [15], a number of factors limiting the adoption of cloud computing in the Czech Republic include data security, IT governance, service availability as well as dependence on service providers.

According to a study in Bangladesh [16], some major factors contributing to the adoption of cloud computing in the University of Dhaka in Bangladesh consist of lack of adequate infrastructure, service availability and utility in education. Moreover, another work of research [17] refers to problems related to privacy and security as 
challenges faced in the process of the utilization of cloud computing in Sudan's higher education.

Also, in a study in Vietnam [10], it was stated that factors such as performance expectancy (perceived usefulness), social impacts, hedonic motivation and habit all affect cloud-based e-learning adoption.

Furthermore, the readiness as well as basis for the adoption of cloud computing in the higher education was explored by a study in the United Arab Emirates [9]. It was established by this study that after feeling such a technology can be easily utilized, the probability of users adopting cloud services in their educational systems increases. Therefore, this determines that ease of use plays an important role in the corresponding attitudes and behaviours of university students. Also, another study exists regarding the advantages as well as challenges in the utilization of cloud computing in e-learning [18]. According to most aforementioned studies, security acts as an important factor in the adoption of cloud-based e-learning systems.

Towards a comparison between the Middle East and Europe, a work of research was carried out in which the adoption of cloud computing as well as its intercontinental variation was the main topic of discussion. The results indicated that European countries had a greater tendency to adopt upgraded technology, whereas the traditional technology was still favoured in the Middle East. In regard to the security issues remaining to be handled, specific centres are set up in Europe while Middle Eastern nations namely Oman and Qatar are dealing with security problems consisting of privacy, integrity and security. Moreover, in the Middle East, education via cloud computing is only going through its initial phase [19].

\section{$4 \quad$ Research Framework}

\subsection{Technology acceptance model}

Among the many theoretical models for explaining the adoption of particular systems or services, the TAM proposed by Davis is one of the most widely used frameworks [20]. The TAM model assumes that when someone is introduced to a new technology, his or her decision to use it will be influenced by a number of factors [21]. TAM is one of the most popular theories that are applied extensively in order to explain the factors responsible for the adoption of technology [22]. Many works of research have demonstrated that perceived usefulness and ease of use influence the ways users accept a new innovation or system. This suggests that computer usage is decided by a behavioural intention to use a system, which is jointly determined by perceived ease of use and perceived usefulness. Previous studies indicate that if an individual perceives a system to be easy to use, he or she is more likely to perceive the system to be useful as well $[23,24]$.

The TAM model has been widely employed in the context of cloud computing adoption $[9,25]$, learning management systems [21] and the examination of factors affecting mobile devices in the educational sector [26]. Although the TAM has been integrated within the educational and technology perspective since the 1980s, it is 
extended and expanded in a different context whenever a new technology is introduced [9].

\subsection{Hypothesis development}

Figure 1 consists of a summary of the research model as well as the hypotheses. According to previous studies, security and trust are important factors in the adoption of new technology. Furthermore, the TAM is utilized in this study. Previous literature in the field of technology acceptance has proposed various factors including perceived ease of use (PEOU) and perceived usefulness (PU) and has proven their influence on the behavioural intention to use and adopt new technologies [27].

Perceived usefulness: Davis [20] defines perceived usefulness (PU) as the degree to which a person believes a system can enhance his or her job performance. According to this study, learners concluded that the corresponding cloud-based elearning system was helpful in regard to their performance. Moreover, the individual learner would be more satisfied with e-learning [10]. Therefore, this study suggests the following hypothesis:

H1: Perceived usefulness has a positive effect on cloud-based e-learning intention.

Perceived ease of use: It is defined as the degree of ease associated with the usage of a system [10]. Simplicity in a system develops the users' ability to utilize the system towards the enhancement of their performance. Usage of the system increases performance but the evaluation of the effort it will take to use such a system is also important [28]. Therefore, this study suggests the following hypothesis:

H2: Perceived ease of use has a positive effect on cloud-based e-learning intention.

Trust and Security: The key goals of information security are to protect the confidentiality, integrity and availability of data regardless of the form the data may take [29]. Security is evaluated as a cloud-computing risk by universities and organizations. In the context of this study, students are expected to be more likely motivated to use cloud-based e-learning systems if they trust such systems. Therefore, this study suggests the following hypothesis:

H3: Trust and security have a positive effect on cloud-based e-learning intention.

Need: Universities need cloud computing due to ever-changing technological improvements and also to satisfy their technological needs [30]. In this respect, need is added to this study to represent the importance and need of cloud-based e-learning systems for students and lecturers. Therefore, this study suggests the following hypothesis:

H4: Need has a positive effect on cloud-based e-learning intention.

Innovativeness as a moderator: Agarwal and Prasad [31] proposed innovativeness in the domain of information technology as a new construct, developed from previous works including Rogers'. It is defined as the "willingness of an individual to try out any new information technology". Moreover, it is understood as a trait and conceptualized to be invariant across situational considerations. Many studies have employed innovativeness to adopt new technologies. For instance, it is used with the UTAUT2 Model [10]. A new contribution of this study to research of this kind is the utilization of innovativeness as a moderator with the TAM model, 
along with need as a new variable which is added to this model, as mentioned above. Therefore, this study suggests the following hypothesis:

H5: Innovativeness will moderate the relationship between perceived usefulness and cloud based e-learning intention.

H6: Innovativeness will moderate the relationship between perceived ease of use and cloud based e-learning intention.

H7: Innovativeness will moderate the relationship between Trust and Security and cloud based e-learning intention.

H8: Innovativeness will moderate the relationship between Need and cloud based e-learning intention.

H9: Innovativeness has positive effect on cloud based e-learning intention.

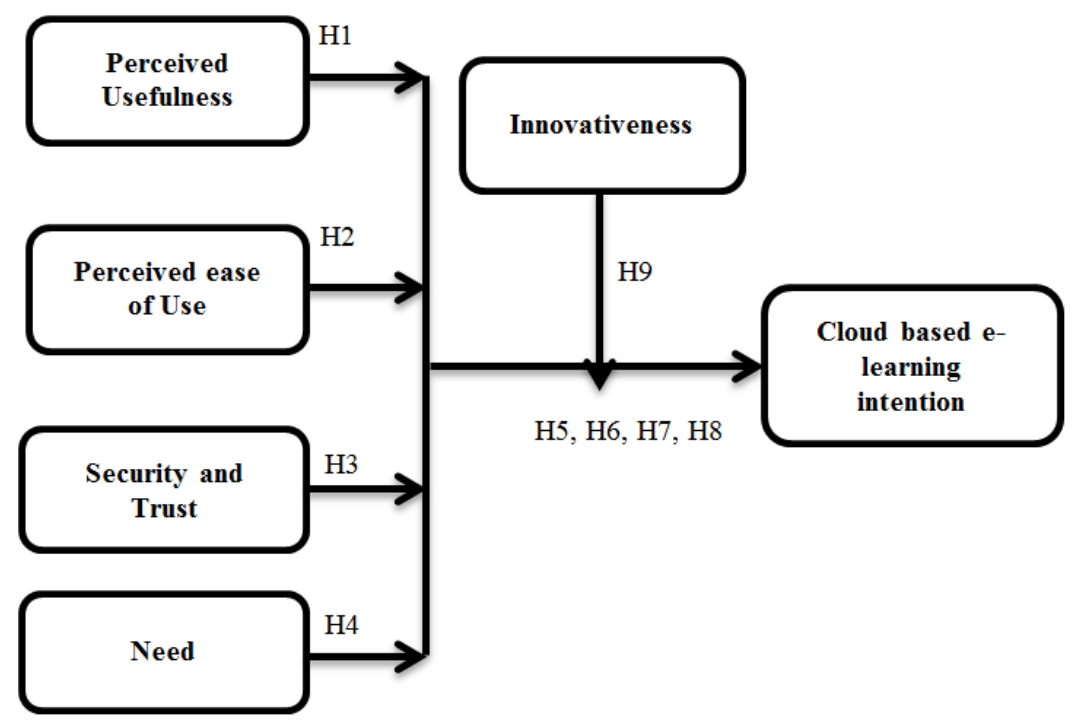

Fig. 1. Research Framework

\section{$5 \quad$ Methodology}

\subsection{Population and sampling}

The target population in this study is higher education students and lecturers in Malaysian universities. The participants in this study were lecturers and students from two important universities in Malaysia, Universiti Sains Malaysia (USM) and Universiti Utara Malaysia (UUM). The study used convenience sampling for data collection [32].

The sample size of 200 to 500 is considered sufficient for multivariate data analysis [33]. Also, researchers have asserted that a sample size larger than 30 and less than 500 is appropriate for many works of research [34]. 


\subsection{Instrumentation}

In this study, the survey questions are divided into two sections A and B. Section A consists of the demographic profile of the respondent. This section seeks information regarding respondents, including their gender, age, level of education, position and experience. Section B includes a set of 21 questions compiled to represent the constructs. Furthermore, perceived ease of use (PEU) and usefulness (PU), trust and security (TS), need (N), innovativeness (INN) as a moderator and finally, cloud computing-based e-learning intention (CCEI) are adopted from [10], [29], and [30].

The measurement of the items is done by using seven Likert-type scales. A sevenpoint scale is used to allow respondents in the universities to express how much they agree or disagree with a particular statement. Each point of the scale is defined as follows: $1=$ Strongly disagree, $2=$ Disagree, $3=$ Slightly disagree, $4=$ Neither agree nor disagree, $5=$ Slightly agree, $6=$ Agree, $7=$ Strongly agree.

The questionnaire is written in the English language and the contents are then proofread and checked for meaning and grammar. In order to ensure the validity of items in the measurement of the research variables, the questionnaire was sent to four experts for review. The experts' opinions are expected to enhance the conceptual research framework variables as well as the survey instrument and to consequently cause the research study to become more scientific and authentic.

\subsection{Data collection}

The data is collected by online using Google forms, 265 respondents were obtained. The demographic information of the respondents is summarized in Table 1.

Table 1. Profile of the respondents $(n=265)$

\begin{tabular}{|l|l|c|c|}
\hline \multicolumn{1}{|c|}{ Variable } & \multicolumn{1}{|c|}{ Description } & Number of Respondents & \% \\
\hline \multirow{4}{*}{ Gender } & Female & 142 & 53.6 \\
\cline { 2 - 4 } & Male & 123 & 46.4 \\
\hline \multirow{5}{*}{ Age } & $19-23$ & 124 & 46.8 \\
\cline { 2 - 4 } & $24-30$ & 84 & 31.7 \\
\cline { 2 - 4 } & $31-40$ & 50 & 18.9 \\
\cline { 2 - 4 } & Above 40 & 7 & 2.6 \\
\hline \multirow{5}{*}{ Education } & Bachelor's degree & 240 & 90.6 \\
\cline { 2 - 4 } & Master's degree & 7 & 2.6 \\
\cline { 2 - 4 } & PhD Degree & 18 & 6.8 \\
\hline \multirow{5}{*}{ Experition } & Lecture & 16 & 6.0 \\
\cline { 2 - 4 } & Postgraduate & 28 & 10.6 \\
\cline { 2 - 4 } & Undergraduate & 221 & 83.4 \\
\hline & Good in Cloud Computing & 40 & 15.1 \\
\cline { 2 - 4 } & Average in Cloud Computing & 176 & 66.4 \\
\cline { 2 - 4 } & Bad in Cloud Computing & 49 & 18.5 \\
\hline
\end{tabular}




\section{Data Analysis and Results}

The quantitative data collected have been analyzed using Smart Partial Least Square M3 Version 3.2.7 and SPSS version 22. PLS-SEM is a technique to estimate causal relationship among variables. Following a two-stage analytical procedure, measurement model is analyzed first to assess the reliability and validity of the instrument and then hypotheses were tested through a structural model.

\subsection{Descriptive statistics of the variables}

The mean of all the six latent variables varies from 5.02 to 5.57 , whereas the standard deviation varies from 1.039 to 1.363 on a seven-point Likert scale. However, the values of the mean of all the variables were found to be higher than the midpoint 3.50. The dispersion of values reported through standard deviation indicates that the highest value shown was from innovativeness and the lowest value shown was from perceived usefulness.

\subsection{Measurement model assessment}

The main loadings for all the question items explained are more than 0.7 for all the latent variables (model variables present in the framework). The minimum value of the main loading is 0.810 and the maximum value is 0.969 . AVE to measures the level of variance captured by a construct versus the level due to measurement error, values above 0.7 are considered very good, whereas, the level of 0.5 is acceptable. It is found that all the AVE values are greater than 0.7, which shows that the convergent validity is very good. Meanwhile, the Composite Reliability is a less biased estimate of reliability than Cronbach's Alpha, the acceptable value of CR is 0.7 and above [35]. The values in Table 2 are shown to be larger than 0.7, which indicates high levels of internal reliability among latent variables.

Table 2. Results of measurement model assessment

\begin{tabular}{|c|c|c|c|c|c|}
\hline Latent variable & Question Items & Main Loading & AVE & CR & $\begin{array}{c}\text { Cronbach's } \\
\text { Alpha }\end{array}$ \\
\hline \multirow{3}{*}{$\begin{array}{l}\text { Cloud computing-based } \\
\text { e-learning Intention }\end{array}$} & CCEI1 & 0.953 & \multirow{3}{*}{0.904} & \multirow{3}{*}{0.966} & \multirow{3}{*}{0.947} \\
\hline & CCEI2 & 0.943 & & & \\
\hline & CCEI3 & 0.956 & & & \\
\hline \multirow{4}{*}{ Innovativeness } & INN1 & 0.829 & \multirow{4}{*}{0.702} & \multirow{4}{*}{0.904} & \multirow{4}{*}{0.858} \\
\hline & INN2 & 0.858 & & & \\
\hline & INN3 & 0.810 & & & \\
\hline & INN4 & 0.854 & & & \\
\hline \multirow{2}{*}{ Need } & N1 & 0.966 & \multirow{2}{*}{0.937} & \multirow{2}{*}{0.967} & \multirow{2}{*}{0.932} \\
\hline & $\mathrm{N} 2$ & 0.969 & & & \\
\hline \multirow{3}{*}{ Perceived Ease of Use } & PEU1 & 0.888 & \multirow{3}{*}{0.821} & \multirow{3}{*}{0.948} & \multirow{3}{*}{0.927} \\
\hline & PEU2 & 0.909 & & & \\
\hline & PEU3 & 0.938 & & & \\
\hline
\end{tabular}




\begin{tabular}{|c|c|c|c|c|c|}
\hline & PEU4 & 0.888 & & & \\
\hline \multirow{4}{*}{ Perceived Usefulness } & PU1 & 0.898 & \multirow{4}{*}{0.819} & \multirow{4}{*}{0.948} & \multirow{4}{*}{0.926} \\
\hline & PU2 & 0.913 & & & \\
\hline & PU3 & 0.928 & & & \\
\hline & PU4 & 0.880 & & & \\
\hline \multirow{4}{*}{ Trust and Security } & TS1 & 0.917 & \multirow{4}{*}{0.839} & \multirow{4}{*}{0.954} & \multirow{4}{*}{0.936} \\
\hline & TS2 & 0.928 & & & \\
\hline & TS3 & 0.911 & & & \\
\hline & TS4 & 0.909 & & & \\
\hline
\end{tabular}

*CR: composite reliability, AVE: average variance extracted

With regard to convergent and discriminant validity, the test described by Fornell and Larcker [36] was applied. They state that the square root of the average variance extracted (diagonal elements in Table 3) should be higher than the correlations between the constructs (off-diagonal elements in Table 3). As this is given for all constructs it can be concluded that they are valid and work as intended.

Table 3. Discriminant validity of Fornell-Larcker Criterion $(n=265)$

\begin{tabular}{|l|c|c|c|c|c|c|}
\hline & CCEI & INN & N & PEU & PU & TS \\
\hline CCEI & $\mathbf{0 . 9 5 1}$ & & & & & \\
\hline INN & 0.708 & $\mathbf{0 . 8 3 8}$ & & & & \\
\hline N & 0.797 & 0.651 & $\mathbf{0 . 9 6 8}$ & & & \\
\hline PEU & 0.706 & 0.699 & 0.704 & $\mathbf{0 . 9 0 6}$ & & \\
\hline PU & 0.788 & 0.661 & 0.762 & 0.800 & $\mathbf{0 . 9 0 5}$ & \\
\hline TS & 0.615 & 0.655 & 0.653 & 0.653 & 0.632 & $\mathbf{0 . 9 1 6}$ \\
\hline
\end{tabular}

One recent method for measuring the discriminant validity in PLS-SEM is the Heterotrait-Monotrait Ratio (HTMT) which was developed by Henseler et al. [37]. HTMT represents the estimate for the construct's correlation with the other constructs that should be smaller than one [38]. A correlation closer to one shows a lack of discriminant validity. Henseler et al. [37] suggested a threshold of 0.90 when the constructs are conceptually similar and 0.85 when the constructs are conceptually different. The results of HTMT assessment in Table 4 are indicating the discriminant validity of the constructs.

Table 4. Discriminant validity of Heterotrait-Monotrait Ratio (HTMT) (n=265)

\begin{tabular}{|l|c|c|c|c|c|c|}
\hline & CCEI & INN & N & PEU & PU & TS \\
\hline CCEI & & & & & & \\
\hline INN & 0.782 & & & & & \\
\hline N & 0.848 & 0.723 & & & & \\
\hline PEU & 0.752 & 0.780 & 0.756 & & & \\
\hline PU & 0.839 & 0.736 & 0.818 & 0.862 & & \\
\hline TS & 0.652 & 0.729 & 0.698 & 0.700 & 0.674 & \\
\hline
\end{tabular}




\subsection{Structural model assessment}

Testing the hypotheses and path coefficients in SmartPLS 3 entails the utilization of bootstrapping, a non-parametric statistical approach that draws many sub-samples from the sample data and examines models for each sub-sample [35]. For bootstrapping options, $5000 \mathrm{sub}$-samples, one-tailed in regard to the hypotheses, were proposed to be positive (+) and a significance level of 0.05 was employed. The results of hypothesis and direct relationship testing are presented in Table 5, showing that $\mathrm{N}$ and PU have a significant effect on CCEI. Regarding the moderating effect, the results demonstrate that $\mathrm{INN} * \mathrm{~N}->$ CCEI is significant.

Table 5. Results of path analysis

\begin{tabular}{|l|l|c|c|c|c|l|}
\hline \multicolumn{1}{|c|}{ Hypothesis } & \multicolumn{1}{|c|}{ Path } & $\begin{array}{c}\text { Beta } \\
\text { value }\end{array}$ & SE & t-value & p-values & \multicolumn{1}{|c|}{ Result } \\
\hline H9 & INN -> CCEI & 0.225 & 0.068 & 3.302 & 0.000 & N/A \\
\hline H4 & N -> CCEI & 0.427 & 0.088 & $4.857 * * *$ & 0.000 & Supported \\
\hline H2 & PEU -> CCEI & -0.020 & 0.081 & 0.244 & 0.404 & Not Supported \\
\hline H1 & PU -> CCEI & 0.355 & 0.080 & $4.446 * * *$ & 0.000 & Supported \\
\hline H3 & TS -> CCEI & -0.023 & 0.057 & 0.410 & 0.341 & Not Supported \\
\hline H8 & INN*N -> CCEI & -0.152 & 0.065 & $2.325 *$ & 0.010 & Supported \\
\hline H6 & INN*PEU -> CCEI & 0.082 & 0.069 & 1.184 & 0.118 & Not Supported \\
\hline H5 & INN*PU -> CCEI & 0.017 & 0.066 & 0.255 & 0.400 & Not Supported \\
\hline H7 & INN*TS -> CCEI & 0.002 & 0.067 & 0.025 & 0.490 & Not Supported \\
\hline
\end{tabular}

Note: ${ }^{*} \mathrm{p}<0.05, \mathrm{t}>1.645,{ }^{*} \mathrm{p}<0.01, \mathrm{t}>2.33, * * * \mathrm{p}<0.001, \mathrm{t}>3.06$ (one tailed); SE: Standard Error

Coefficient of determination $\left(\mathrm{R}^{2}\right)$ refers to the effect of independent variables on the dependent variables. The R-squared value ranges from 0 to 1 , with 1 defining perfect predictive accuracy. Hair et al. [39] proposed a rule of thumb for acceptable $\mathrm{R}^{2}$ values with $0.75,0.50$, and 0.25 described as substantial, moderate and weak respectively.

Regarding the value of the coefficient of determination $\left(\mathrm{R}^{2}\right)$ for the direct effect of the latent variables (PU, PEU, TS, N and INN) on CCEI, a value of 0.741 is displayed in Figure 2. According to Hair et al. [39], $\mathrm{R}^{2}$ estimates were substantial, which indicates the high quality of the proposed model.

\subsection{Predictive relevance of the model $\left(Q^{2}\right)$}

Predictive relevance statistics are used to measure the quality of the PLS path model, which is calculated via blindfolding procedures [40]. Also, cross-validated redundancy was performed. The $\mathrm{Q}^{2}$ criterion recommends that the conceptual model can predict the endogenous latent constructs. In PLS, the $\mathrm{Q}^{2}$ values measured must be greater than zero for a particular endogenous latent construct (independent). As shown in Figure 3, the $\mathrm{Q}^{2}$ value for this study model was equal to 0.623 , higher than the threshold limit. Therefore, it supports that the path model's predictive relevance was adequate for the endogenous construct. 


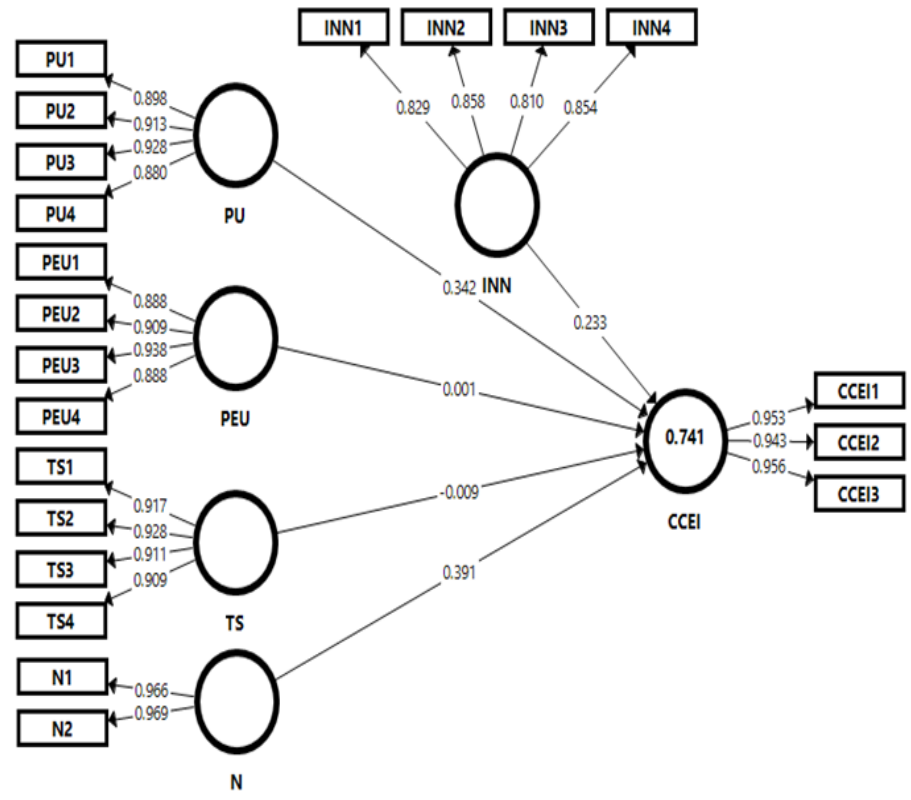

Fig. 2. PLS-Path analysis of R-square values $(n=265)$

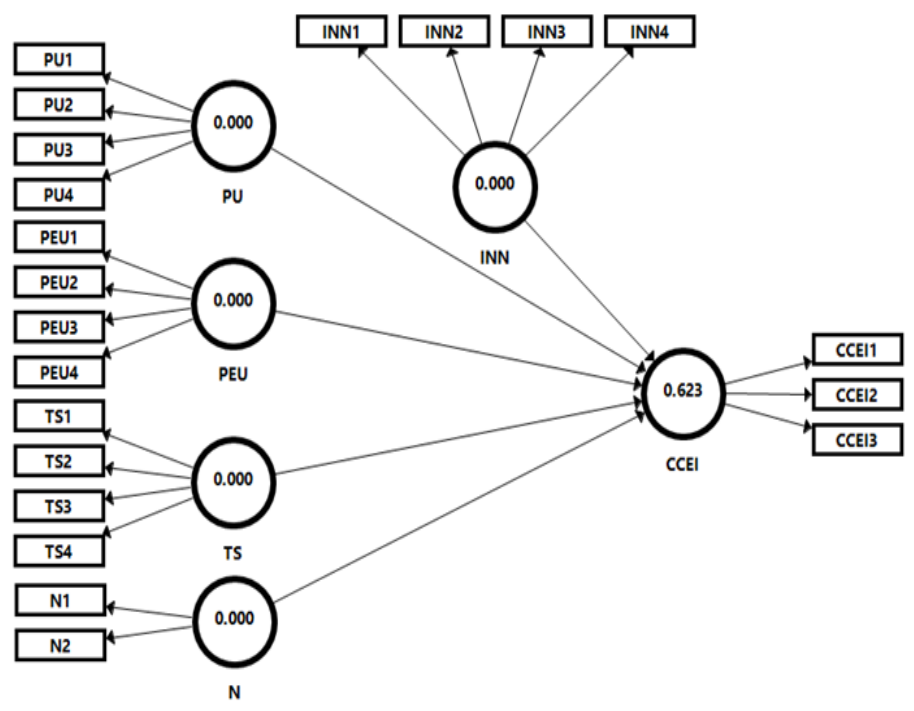

Fig. 3. Blindfolding $(\mathrm{DV})\left(\mathrm{Q}^{2}=0.623>0\right)$ 


\subsection{Goodness-of-fit index}

The Goodness-of-Fit (GOF) of a statistical model is used to describe how well it fits into a set of observation's models [41]. The GOF values lie between 0 and 1 , where values of 0.10 (small), 0.25 (medium), and 0.36 (large) indicate the global validation of the path model. The GOF is calculated by using the equation below:

$\mathrm{GOF}=\mathrm{SQRT}(($ Average AVE) * Average R Square))

It was calculated from Table 6 that the GOF index for this study model was measured as 0.781 , is above 0.36 for an excellent PLS model for the data.

Table 6. Goodness of Fit (GOF)

\begin{tabular}{|c|c|c|c|}
\hline Dependent Variables & Average of AVE & R Square & GoF \\
\hline Cloud computing-based e-learning Intention & 0.824 & 0.741 & 0.781 \\
\hline
\end{tabular}

\section{$7 \quad$ Discussion and Conclusion}

The development in e-learning has produced innovative functions towards helping education and learning endeavours of teachers and students. Numerous educational frameworks and functions, particularly e-learning, have been introduced in recent years. Thus, understanding the intention of teachers and students towards using cloudbased e-learning applications is crucial. This study validated the proposed theoretical model for predicting the intention to use cloud-based e-learning among teachers and students in two Malaysian universities. Moreover, five important factors were taken into consideration, including perceived usefulness, perceived ease of use, trust and security, need and cloud computing-based e-learning intention with the moderating factor of innovativeness.

This study discovered that perceived usefulness has a positive and significant effect on cloud computing-based e-learning. Furthermore, the results support prior studies which have shown that perceived usefulness has a significant effect in adopting cloud computing in higher education [42]. According to these results, it is quite clear that if students and lecturers perceive cloud computing-based e-learning as a technology which will be beneficial to them, they will be generally open to using it as well as learning it in order to perform their tasks.

Another important finding of this study is that perceived ease of use holds no significance in cloud computing adoption, similar to another work of research [43]. As such, collectively, the insignificance of perceived ease of use suggests that resistance towards new technologies may not be as pivotal as it once was [44]. Another explanation for the insignificance of perceived ease of use is that current university students have grown up with computers all around them in their homes and schools. Moreover, they have experienced everything regarding computers, from large "old-fashioned" desktops to the latest phones which have all up-to-date computing capabilities and are yet small enough to fit in their pocket. Although these students may not actually understand the real technology behind the screen, they tend to be 
more likely to accept cloud computing if their "perceived ease of use" is high, which means that less effort is required to learn how to use it [42].

Trust and security were found not to have a significant effect on cloud computingbased e-learning intention, since this study is still in an early stage for respondents. This finding suggests that it may be worthwhile for universities to educate students about the security of cloud computing-based e-learning before introducing it as part of their work.

Another essential and significant factor in this study is need. The technological needs of universities arise with the emergence of a competitive global environment. As mentioned in prior research [30], one of the five reasons for the usage of cloud computing services in businesses is that these services can support their various business needs.

As a moderating effect in this study, it was discovered that perceived usefulness and ease of use with innovativeness towards cloud computing-based e-learning systems are insignificant. With respect to the effect of perceived usefulness in the adoption of different technologies, perceived usefulness with innovativeness holds no effect. According to results from previous research, innovativeness captures an individual's willingness to try novel information technology [31]. Therefore, the effect of trying new technologies might perhaps reduce the importance of usefulness. This is due to the fact that cloud computing-based e-learning is still a relatively new topic and many might not comprehend the importance of it yet.

\section{Acknowledgement}

This study was funded by a research university grant from Universiti Sains Malaysia (1001/PJJAUH/8016029). The first author received financial support through the university postdoctoral program.

\section{References}

[1] A. Jain, and U. S. Pandey, "Role of Cloud Computing in Higher Education", International Journal of Advanced Research in Computer Science and Software Engineering, vol. 3, no. 7, pp. 966-972, 2013.

[2] E. Yadegaridehkordi, N. A. Iahad, and S. Asadi, "Cloud Computing Adoption Behaviour: an Application of the Technology Acceptance Model", Journal of Soft Computing and Decision Support Systems, vol. 2, no. 2, pp. 11-16, 2015.

[3] Q. N. Naveed, and N. Ahmad, "Critical Success Factors (CSFs) for Cloud-Based eLearning", International Journal of Emerging Technologies in Learning (iJET), vol. 14, no. 1, pp. 140-149, 2019. https://doi.org/10.3991/ijet.v14i01.9170

[4] M. Ali, S. M. Hossain, and T. Ahmed, "Effectiveness of E-learning for university students: evidence from Bangladesh", Asian Journal of Empirical Research, no. 8, vol. 10, pp. 352360,2018

[5] V. G. da Silva and R. M. S. de Souza, "E-Learning, B-Learning, M-Learning and the Technical and Pedagogical Aspects on the New Platform Trends as Massive open Online 
Courses", Conference: International Technology, Education and Development Conference, 2016. https://doi.org/10.21125/iceri.2016.0239

[6] B. Dong, Q. Zheng, M. Qiao, J. Shu, and J. Yang, "BlueSky Cloud Framework: An Elearning Framework Embracing Cloud Computing", Springer, Berlin, Heidelberg, vol. 5931, pp. 577-582, 2009. https://doi.org/10.1007/978-3-642-10665-1_55

[7] W. Zhang, and Y. Zhu, "A new E-learning model based on elastic cloud computing for distance education", Eurasia Journal of Mathematics, Science and Technology Education, vol. 13, no. 12, pp. Page no. 1-20. https://doi.org/10.12973/ejmste/80800

[8] P. Mell, and T. Grance, "The NIST definition of cloud computing", 2011. Retrieved from http://csrc.nist.gov/publications/nistpubs/800-145/SP800-145.pdf. https://doi.org/10.6028/NIST.SP.800-145

[9] Z. Shana, and E.S. Abulibdeh, "Cloud Computing Issues for Higher Education: Theory of Acceptance Model”, International Journal of Emerging Technologies in Learning (iJET), vol. 12, no. 11, pp. 168-184, 2017. https://doi.org/10.3991/ijet.v12.i11.7473

[10] T.D Nguyen, T. M. Nguyen, QT. Pham, amd S. Misra, "Acceptance and Use of ELearning Based on Cloud Computing: The Role of Consumer Innovativeness", In: Murgante B. et al. (eds) Computational Science and Its Applications - ICCSA, pp 159174, 2014. https://doi.org/10.1007/978-3-319-09156-3_12

[11] L.Wang, G. V. Laszewski, A. Younge, X. He, M. Kunze, J. Tao, and C. Fu, "Cloud Computing: a Perspective Study", New Generation Computing, vol. 28, no. 2, pp. 137-146, 2010. https://doi.org/10.1007/s00354-008-0081-5

[12] G. Riahi, "E-learning Systems Based on Cloud Computing: A Review", Procedia Computer Science, vol. 62, pp. 352-359, 2015. https://doi.org/10.1016/j.procs.2015.08.415

[13] N. Sultan, "Cloud computing for education: A new dawn?" International Journal of Information Management, vol. 30, no. 2, pp. 109-116, 2010. https://doi.org/10.1016/ j.ijinfomgt.2009.09.004

[14] A. Shahzad, N., A. Ismail, A. G. Golamdin, "Opportunity and Challenges using the Cloud Computing in the Case of Malaysian Higher Education Institutions," International Journal of Management Science and Information Technology, vol. 20, no. 20, pp. 1-18, 2016.

[15] G. Feuerlicht, and N. Margaris, "Cloud Computing Adoption: A comparative Study", Cloud Computing Research Group, 2012.

[16] J. Sultana, Md. F. Mazmum, and N. J. Nipa, "Factors Affecting Cloud Computing Adoption in Higher Education in Bangladesh: A Case of University of Dhaka," Applied and Computational Mathematics, vol. 6, no. 3, pp. 129-136, 2017. https://doi.org/10. 11648/j.acm.20170603.11

[17] M. S. Adress, M. K. Omer, and O. E. Sheta, "Cloud Computing Adoption in the Higher Education (Sudan as a model): A SWOT Analysis," American Journal of Information Systems, Science and Education Publishing, vol. 4, no. 1, pp.7-10, 2016. http://pubs. sciepub.com/ajis/4/1/2

[18] A. Fernández, D. Peralta, F. Herrera, and J. M. Benítez, “An Overview of E-Learning in Cloud Computing", Workshop on Learning Technology for Education in Cloud (LTEC'12). Advances in Intelligent Systems and Computing, vol. 173. Springer, Berlin, Heidelberg, 2012. https://doi.org/10.1007/978-3-642-30859-8_ 4

[19] M. S. I. Abdullahi, N. Salleh, A. Nordin, and A. A. Alwan, "Cloud-based learning system for improving students' programming skills and self-efficacy", Journal of Information and Communication Technology, vol. 17, no. 4, pp. 629-651, 2018. http://repo.uum.edu. $\underline{\text { my/id/eprint/24942 }}$ 
[20] F. D. Davis, "Perceived usefulness, perceived ease of use, and user acceptance of information technology", MIS quarterly, vol. 13, no. 3, pp. 319-340, 1989. https://www.j stor.org/stable/249008

[21] S. Binyamin, M. J. Rutter, and S. Smith, "Extending the Technology Acceptance Model to Understand Students' use of Learning Management Systems in Saudi Higher Education”, International Journal of Emerging Technologies in Learning (iJET), vol. 14, no. 3, pp. 421, 2019. https://doi.org/10.3991/ijet.v14i03.9732

[22] M. Kalogiannakis, and S. Papadakis, "Evaluating pre-service kindergarten teachers' intention to adopt and use tablets into teaching practice for natural sciences", International Journal of Mobile Learning and Organisation, vol. 13, no. 1, pp. 113-127, 2019. https:// doi.org/10.1504/ijmlo.2019.10016617

[23] D. A. Adams, R. R. Nelson, and P. Todd, "Perceived usefulness, ease of use, and usage of information technology: a replication”, MIS Q, vol. 16, no. 2, pp. 227-247, 1992. https:// doi.org/10.2307/249577

[24] I. Arpaci, "Understanding and predicting students' intention to use mobile cloud storage services", Computers in Human Behavior, vol. 58, pp. 150-157, 2016. https://doi.org/10. 1016/j.chb.2015.12.067

[25] T. S. Behrend, E. N. Wiebe, J. E. London, and E. C. Johnson, "Cloud computing adoption and usage in community colleges", Behaviour \& Information Technology, vol. 30, no. 2, pp. 231-240, 2011. https://doi.org/10.1080/0144929X.2010.489118

[26] S. Papadakis, "Evaluating pre-service teachers' acceptance of mobile devices with regards to their age and gender: a case study in Greece", International Journal of Mobile Learning and Organisation, vol. 12, no. 4, pp. 336-352, 2018. https://doi.org/10.1504/IJMLO .2018 .095130

[27] M. R. Jaradat, J. Imlawi, and A. Mashaqba, "Investigating the Moderating Effects of SelfEfficacy, Age and Gender in the Context of Nursing Mobile Decision Support Systems Adoption: A Developing Country Perspective”, International Journal of Interactive Mobile Technologies (iJIM), vol. 12, no. 2, pp. 113-129, 2018. https://doi.org/10.3 991/ijim.v12i2.8081

[28] V. D. Heijden, "User Acceptance of Hedonic Information Systems", MIS Quarterly vol. 28, no. 4, pp. 695-704, 2004. https://doi.org/10.2307/25148660

[29] A. Tarhini, R. Masa'deh, K. A. Al-Busaidi, A. Bany Mohammed, and M. Maqableh,"Factors influencing students' adoption of e-learning: a structural equation modeling approach", Journal of International Education in Business, vol. 10, no. 2, pp. 164-182, 2017. https://doi.org/10.1108/JIEB-09-2016-0032

[30] E. Akar, and S. Mardikyan, "Analyzing Factors Affecting the Adoption of Cloud Computing: A Case of Turkey," KSII Transactions on Internet and Information Systems, vol. 10, no. 1, pp. 18-37, 2016. https://doi.org/10.3837/tiis.2016.01.002

[31] R. Agarwal, and J. Prasad, "A conceptual and operational definition of personal innovativeness in the domain of information technology", Information Systems Research, vol. 9 no. 2, 204-215, 1998. https://pubsonline.informs.org/doi/10.1287/isre.9.2.204

[32] J. W. Creswell "Qualitative inquiry and research design: Choosing among five approaches (3rd ed.)", Thousand Oaks, CA: Sage, 2013. https://doi.org/10. $\underline{1086 / 317417}$

[33] J. F. Jr. Hair, W. C. Black, B. J. Babinm and R. E. Anderson, "Multivariate data analysis (7th Ed.)". New Jersey: Pearson Prentice Hall, 2010.

[34] U. Sekaran, and R. Bougie, "Research methods for business: a skill building approach", 5, Wiley, 2010. 
[35] J. F. Hair, G. T. Hult, C. M. Ringle and M. Sarstedt, "A Primer on Partial Least Squares Structural Equation Modeling (PLS-SEM)”, 2 ed., Los Angeles, CA: SAGE, 2017. https:// doi.org/10.3926/oss. 37

[36] C. Fornell, and D. F. Larcker, "Evaluating structural equation models with unobservable variables and measurement error", Journal of Marketing Research, vol. 18, no. 1, pp. 3950, 1981. 1981. https://doi.org/10.1177/002224378101800104

[37] J. Henseler, C. M. Ringle and M. Sarstedt, "A New Criterion for Assessing Discriminant Validity in Variance-Based Structural Equation Modeling," Journal of the Academy of Marketing Science, vol. 43, no. 1, pp. 115-135, 2015. https://doi.org/10.1007/s11747-014 0403-8

[38] J. Henseler, G. Hubona and P. A. Ray, "Using PLS Path Modeling in New Technology Research: Updated Guidelines," Industrial Management \& Data Systems, vol. 116, no. 1, pp. 2-20, 2016. https://doi.org/10.1108/IMDS-09-2015-0382

[39] J.F. Hair, M. Sarstedt, L. Hopkins, and V. G. Kuppelwieser,"Partial least squares structural equation modeling (PLS-SEM)", European Business Review, vol. 26, no. 2, pp. 106-121, 2014. https://doi.org/10.1108/EBR-10-2013-0128

[40] J. F. Hair, M. Sarstedt, C. M. Ringle,. and J. A. Mena, "An assessment of the use of partial least squares structural equation modeling in marketing research", Journal of the Academy of Marketing Science, vol. 40, pp. 414-433, 2012. https://doi.org/10.1007/s11747-011$\underline{0261-6}$

[41] M. Tenenhaus, V. Esposito Vinzi, V, Y.-M. Chatelin, and C. Lauro, "PLS Path Modeling", Computational Statistics \& Data Analysis, vol. 48, pp. 159-205, 2005. https://doi.org/ 10.1016/j.csda.2004.03.005

[42] C. Changchit, "Students' perceptions of cloud computing", International Association for Computer Information Systems, vol. 15, pp. 312-322, 2014.

[43] S. Tripathi, "Moderating effects of age and experience on the factors influencing the actual usage of cloud computing," Journal of International Technology and Information Management, vol. 27, no. 2, pp. 121-158, 2018. https://scholarworks.lib.csusb.edu/jitim/ vol27/iss $2 / 6$

[44] L-Y, Wang, S-L. Lew, S-H. Lau, and M-C. Leow, "Usability factors predicting continuance of intention to use cloud e-learning application", Heliyon, vol. 5, no. 6, pp. 111, 2019. https://doi.org/10.1016/j.heliyon.2019.e01788

\section{Authors}

Dr. Lubna A. Hussein is currently a Post-Doctoral at the School of Distance Education, Universiti Sains Malaysia (USM). Her PhD degree earned from the school of Computer Sciences in the field of Management Information Systems, Universiti Sains Malaysia (USM). Her area of research interested in business IT and Technology Adoption.

Dr. Mohd Faiz Hilmi is currently attached to the School of Distance Education, Universiti Sains Malaysia (USM). He received his DBA from Universiti Sains Malaysia, MBA from Universiti Utara Malaysia and a B.A. degree from Washington State University.

Prior to joining Universiti Sains Malaysia, he had 11 years of multifunctional accomplishments including as IT engineer, IT project/support coordinator, product data specialist and configuration manager in various multinationals corporations. 
Companies and organizations he has been working with include MCMS, Advanced Micro Devices, Celestica, Intel and Motorola. His areas of research interest include Innovation and Technology Management.

Article submitted 2019-10-01. Resubmitted 2020-01-06. Final acceptance 2020-01-12. Final version published as submitted by the authors. 